\title{
TARGETING HYDROTHERMAL ALTERATIONS UTILIZING LANDSAT-8 ANDASTER DATA IN SHAHR-E-BABAK, IRAN
}

\author{
Morteza Safari ${ }^{\mathrm{a}}$, Amin Beiranvand Pour ${ }^{\mathrm{b}}$, Abbas Maghsoudi ${ }^{\mathrm{a}}$ and Mazlan Hashim* \\ ${ }^{a}$ Department of Mining and Metallurgical Engineering, Amirkabir University of Technology, Tehran, Iran \\ ${ }^{\mathrm{b}}$ Geoscience and Digital Earth Centre (Geo-DEC) \\ ${ }^{\mathrm{b}}$ Research Institute for Sustainability and Environment (RISE) \\ Universiti Teknologi Malaysia (UTM) \\ 81310 UTM Skudai, Johor Bahru, Malaysia \\ *Corresponding author: mazlanhashim@utm.my
}

\begin{abstract}
KEY WORDS: Landsat-8, Operational Land Imager (OLI), ASTER, hydrothermal alteration, Shahr-e-babak, porphyry copper
\end{abstract} exploration

\begin{abstract}
:
Shahr-e-Babak tract of the Kerman metalogenic belt is one of the most potential segments of Urumieh-Dokhtar (Sahand-Bazman) magmatic arc. This area encompasses several porphyry copper deposits in exploration, development and exploitation hierarchy. The aim of this study is to map hydrothermal alterations caused by early Cenozoic magmatic intrusions in Shahr-e-Babak area. To this purpose, mineral mapping methods including band combinations, ratios and multiplications as well as PCA and MNF data space transforms in SWIR and VNIR for both ASTER and OLI sensors. Alteration zones according to spectral signatures of each type of alteration mineral assemblages such as argillic, phyllic and propylitic are successfully mapped. For enhancing the target areas false color composites and HSI-RGB color space transform are performed on developed band combinations. Previous studies have proven the robust application of ASTER in geology and mineral exploration; nonetheless, the results of this investigation prove applicability of OLI sensor from landsat-8 for alteration mapping. According to the results, evidently OLI sensor data can accurately map alteration zones. Additionally, the 12-bit quantization of OLI data is its privilege over 8-bit data of ASTER in VNIR and SWIR, thus OLI high quality results, which makes it easy to distinguish targets with enhanced color contrast between the altered and unaltered rocks.
\end{abstract}

\section{INTRODUCTION}

Recognizing hydrothermally altered rocks through remote sensing instruments have been widely and successfully used for exploration of epithermal gold, porphyry copper, massive sulfide and uranium deposits around the world (Gabr et al. 2015; Salles et al. 2015; Wang et al. 2017; Pazand et al. 2013). Since hydrothermal alteration zones associated with porphyry deposits are widespread and well developed, remote sensing plays a vital role in primary exploration stages of this important type of metallic deposit.

Porphyry copper deposits consist of disseminated copper minerals in veins and breccias that are relatively evenly distributed in large volumes of rock, forming high tonnage (greater than 100 million tons), low to moderate grade (0.3-2.0 percent copper) ores. These deposits are generated by hydrothermal fluid processes associated with granitoid porphyry intrusions that alter the mineralogy and chemical composition of the country rocks (Sillitoe 2010).Altered minerals related to porphyry deposits fall in different categories according to similarity of their chemical compositions, this unique chemical composition is responsible for their spectral signatures in electromagnetic spectrum. These minerals have been classified to Phyllic, argillic, potasic and propylitic main assemblages. In argillic and phyllic alterations minerals mostly display Al-OH absorption feature in 1.4 and $2.2 \mu \mathrm{m}$ due to vibrational process, also presence of $\mathrm{Fe} / \mathrm{mg}-\mathrm{OH}$ band in prophylitic alteration causes spectral feature in 0.4 to $1.1 \mu \mathrm{m}$ because of electronic processes, thus most of the spectral features of altered mineral fall in VNIR and SWIR portion of electromagnetic spectrum, where multispectral remote sensing is a powerful tool for detection of these features (Clark 1999; Hunt \& Ashley 1979).

The aim of this investigation is mapping hydrothermally altered minerals related to the porphyry copper deposits implementing Landsat- 8 and ASTER remotely sensed data. This study can evaluate recently launched Landsat- 8 satellite for targeting hydrothermal alterations and compare its results with ASTER which is widely accepted for such cases (Mezned et al. 2010; Jakob et al. 2015). To this purpose robust mapping and digital image processing methods in SWIR and VNIR for both the ASTER and OLI data for Shahr-e-Babak area were carried out. At least 8 well-developed porphyry copper deposits are identified by detailed exploration studies in this arid to semiarid area, therefore this region is a suitable case study for geological remote sensing studies and evaluating Operational Land Imager (OLI) medium spatial resolution multispectral sensor for detecting hydrothermally altered rocks associated with porphyry type deposits. Advantage of OLI sensor over previous Landsat satellites is its narrower band width, two more spectral bands and its enhanced color quality with 12-bit data quantization format, thus this sensor performs much more accurate for mapping different spectral indexes for various applications such as mapping altered minerals (Irons et al. 2012). 


\section{MATERIALS AND METHODS}

\subsection{Geology of the study area}

Shahr-e-Babak is a very important metalogenic country located in the south of Urumieh-Dokhtar (Sahand-Bazman) magmatic arc. This belt has a NW-SE trend and is classified as an Andean volcanic arc. This magmatic arc is the result of a continental plate collision between Arabian and Eurasian plates preceded by Tethys oceanic plate subduction under the Iranian microplate (Regard et al. 2004). Most of the detected porphyry type deposits in Iran are located in the southeastern segment (Kerman tract) and northwestern segment (Azerbaijan tract) of this belt. (Figure 1-B) shows geologic map of our study area, Shahr-e-Babak in Kerman tract which constitutes southern part of this metallogenic country. More than 200 ore deposits including Meiduk and Sar Cheshme world-class porphyry deposits have been detected in Kerman metallogenic country (Ghannadpour et al. 2015). Some of the remarkable porphyry type deposits in Shahr-e-Babak are explicated in (Figure 1-A). According to (Zürcher et al. 2015) the middle-late Miocene world-class Meiduk Cu-Mo-(Au-Ag) porphyry deposit is largest among them. Its circular body have a diameter about $400 \mathrm{~m}$ located in the middle of study area. Meiduk middle-late Miocene granodiorite-diorite-quartz diorite porphyry stock, very similarly to other nearby deposits, intruded to Eocene complex formed by rhyolite lava, breccia, felsic tuff and pyroclastic volcano-sedimentary rocks.

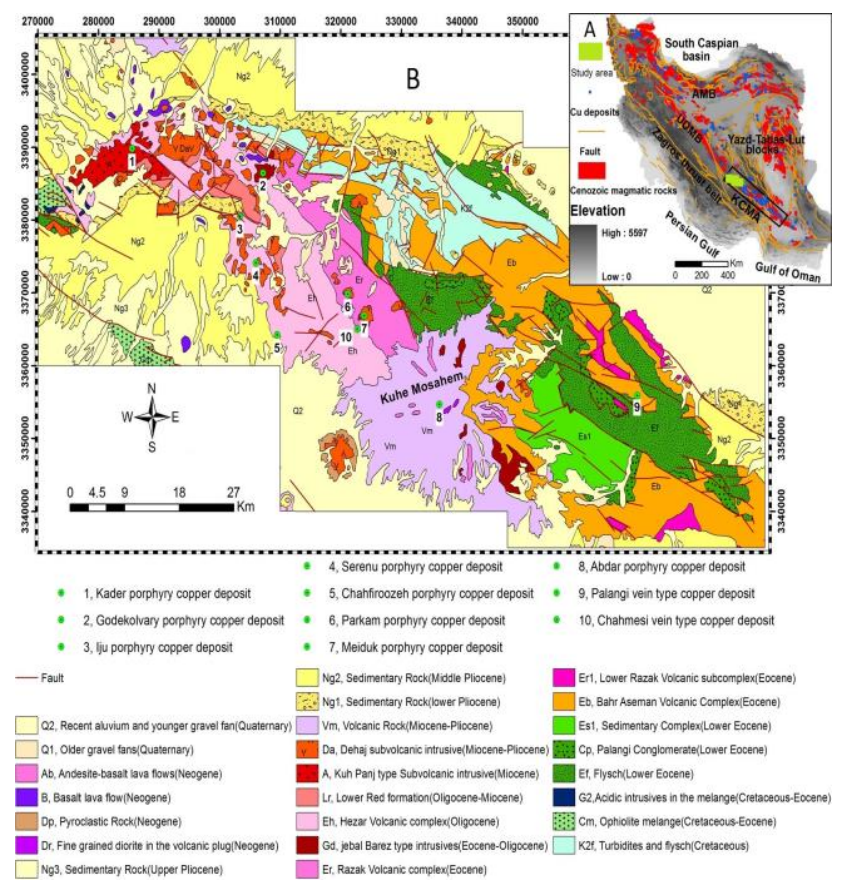

Figure 1. map A shows location of Shahr-e-Babak area in the Urumieh-Dokhtar magmatic arc. Map B shows location of important ore deposits and lithological unites of study area.

\subsection{Remote sensing data}

For this study one cloud-free data set from OLI sensor recorded on October 2016, and two cloud-free ASTER Level 1 Precision Terrain Corrected Registered At-Sensor Radiance (AST_L1T) data in HDF format from February 2006 and June 2007 for full coverage of study area obtained from US Geological Survey (USGS) Earth Explorer server. Gain and offset values available in metadata were applied to recorded Digital Number (DN) values to yield radiance data. Internal Average Relative Reflectance (IARR) atmospheric correction which is recommended by (Aspinall et al. 2002) is used to obtain raw reflectance from radiance data.

For ASTER data two scenes merged by mosaicking process. Then for both OLI and ASTER data a 25-degree westward rotation was applied in order to omit the redundant areas covered by farms and quaternary sediments, then data resized and spatially subsetted to the study area.

\subsection{Image processing methods}

In this study ASTER and Landsat- 8 data were used together in order to evaluate OLI implementation for mapping distribution of hydrothermal alterations associated with potential porphyry ore deposits. To this purpose robust mapping methods in the realm of geological remote sensing including Developed Selective Principal Component Analysis (DSPCA) and Minimum Noise Fraction (MNF) transformation as well as several proposed and developed band combinations, ratios and multiplications for both OLI and ASTER data are performed to map the hydrothermally altered rocks associated with porphyry copper mineralization in the Shahr-e-Babak area. Also False Color Composite (FCC) images, False Color Composite Ratio (FCCR) images and HSI-RGB color space transform Image enhancement techniques were applied to the raw results for better visualizing of target areas.

The most widely used technique to delineate various lithological units is band math (Aleks et al. 2004). Band radioing is one of the most powerful, simple and common band math procedures for mapping hydrothermal alteration zones (Zhang et al. 2007; Rowan et al. 1977). Thus, in order to discriminate hydrothermal alteration zones associated with porphyry copper mineralization in Shahr-e-Babak several band combinations using Landsat-8 and ASTER spectral bands were developed in this study.

\section{RESULTS AND DISCUSSION}

In Figure 2 reflectance spectra of three samples from unaltered rock unites and spectra of one sample from altered unite from Parkam prospect area is plotted, it is evident that value of band 5 - Band 6 and Band 6 - band 7 is higher for altered unites than for unaltered country rocks in Shahr-e-Babak area because of the higher values of bands 5 and 7 than overall value of band 6 in alteration zones. Existence of hydroxyl compositions in clay minerals in altered rocks and their spectral signature causes this phenomenon (Hunt \& Ashley 1979). Based on difference exists between spectral signatures of known altered and unaltered rocks in study area, a FCC composed of band 5 - Band 6, Band 6 - band 7 and band 2 is assigned to RGB color format to delineate hydrothermal alteration zones from background. In Figure 3 this FCC image of mentioned band combinations in RGB color format is shown, blue color represents altered units and purple to yellow color-range is related to different kinds of unaltered country rocks.

Another FCC for discriminating altered rock unites from unaltered unites is composed of $(5 * 6) / 7,(4 * 6) /(5 * 2)$ and $(5 * 6) /(7 * 2)$ OLI spectral bands combinations. The three outlined combinations are developed to indicate different alteration classes, Fe-bearing minerals have relatively higher 
reflection in bands 4 and 6 , but they show absorption in bands 2 and 5 this behavior is intense specially for jarosite, thus for ferric Fe-rich alteration zones $(4 * 6) /(5 * 2)$ term will have a greater value. Term $(5 * 6) / 7$ will indicate argillic zone since clay minerals have strong reflection in band 5 and 6 they also show absorption feature in band 7 between 2.16 to $2.23 \mu \mathrm{m}, \mathrm{Al}-\mathrm{OH}$ is responsible for this absorption feature. Additionally, Silicate minerals show absorption features in band 2 and 7 also they show relative reflection in band 5 and 6 , thus value of $(5 * 6) /(7 * 2)$ term will be higher for phyllic zone (Hunt \& Ashley 1979; Sabins 1999).

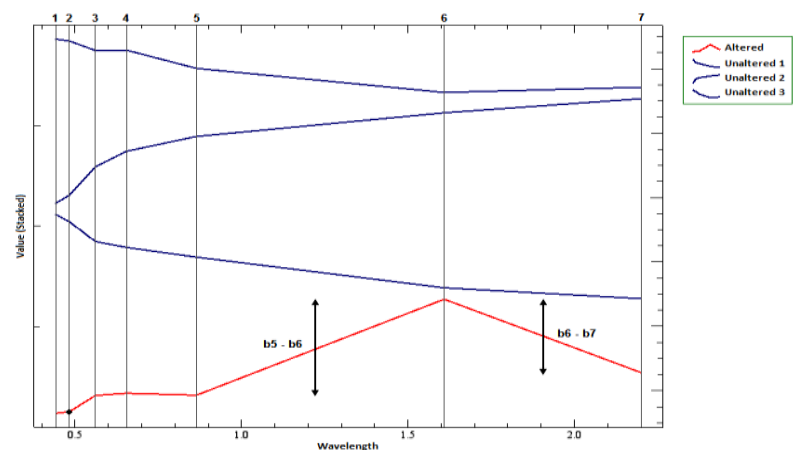

Figure 2. Reflectance spectra of altered and unaltered rock samples gattered from Shahr-e-Babak area.

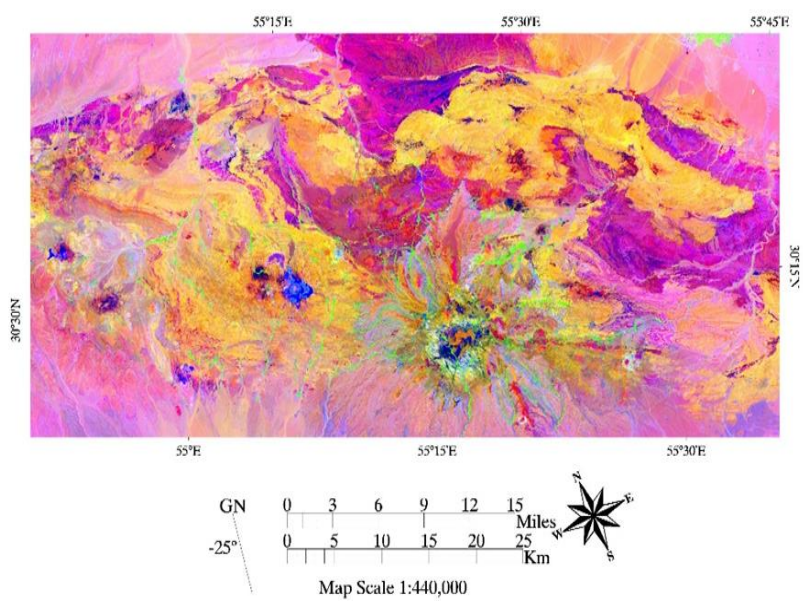

Figure 3. FCC image of $\mathrm{RGB}=2,6-7,5-6$ shows altered rocks as blue color spots.

In Figure 4 altered rocks are represented by dark spots also cyan color spots illustrate mine sites where fresh rock surface has been exposed due to mining activity. The large green spot in middle of the scene depicts Meiduk mine. The proposed OLI band combination robustly separates major lithological unites as well as distinguishing altered rocks in the study area. According to geologic map of Shahr-e-Babak; white, dark violet and olivaceous colors represent Bahr Aseman volcanic complex, Kuhe Mosahem volcanic rocks and Palangi conglomerate complex, respectively. It is evident that proposed OLI band combinations robustly separates lithology unites as well as distinguishing altered rocks in the study area.

Different types of Principal Component Analysis (PCA) have been used in order to extract desired spectral signatures from remotely sensed data (Tangestani \& Moore 2001). Developed Selective Principal Component Analysis (DSPCA) has been successfully proposed and applied on previous Landsat data by
(Crósta \& Moore 1990), thus a DSPCA was carried out in order to map Al-OH bearing altered rocks in this study. The input data of this technique is a subset of spectral bands containing specific spectral characteristics of the target material (Crósta et al. 2003).

As it is represented in Eigenvector loadings (Table 1), OLI bands 2, 5, 6 and 7 are selected since they cover spectral features of $\mathrm{Al}-\mathrm{OH}$ bearing minerals. Positive values of PC 1 are related to albedo data, and negative values of bands 6 and 7 in PC 2 indicate contrast between VNIR and SWIR, moreover negative value of band 5 in PC 3 can be related to vegetation, finally band $7(+0.64)$ and band $6(-0.61)$ loadings demonstrate hydroxylated altered minerals in PC 4.

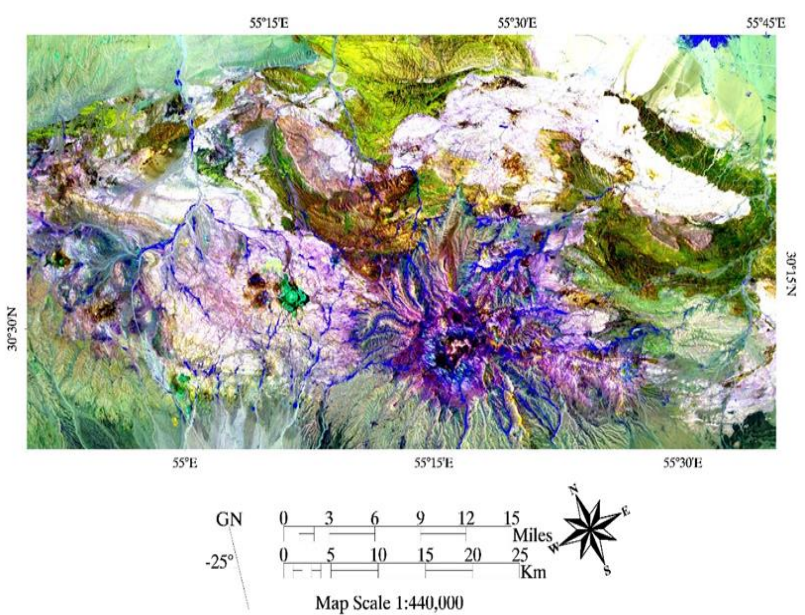

Figure 4. FCC image of RGB $=(5 * 6) / 7,(4 * 6) /(5 * 2),(5 * 6) /(7 * 2)$ shows altered rocks as black spots, also cyan color indicates mining sites, Meiduk mine is distinguished with a cyan color spot in the center of scene.

Table 1. Eigenvector lodgings table for DSPCA eigenvalues, calculated from Shahr-e-Babak OLI data for mapping argillic zone.

\begin{tabular}{c|cccc}
\hline Eigenvector & Band 2 & Band 5 & Band 6 & Band 7 \\
\hline \hline PC 1 & 0.15 & 0.44 & 0.67 & 0.58 \\
PC 2 & 0.27 & 0.84 & -0.28 & -0.38 \\
PC 3 & 0.86 & -0.23 & -0.31 & 0.32 \\
PC 4 & -0.41 & 0.21 & -0.61 & 0.64 \\
\hline
\end{tabular}

To enhance altered zones, PC 4 stretched to rainbow color range and transformed to Red Green Blue (RGB) color format A forward RGB-HSI color transform was applied on this data. The HSI color space constitutes spatial (I) and spectral (H, S) information from a standard RGB (Pohl \& Genderen 1998). OLI band 5 as grayscale image of the area in the background of figure 5 was substituted by I (intensity) component then an inverse RGB-HSI color transform was performed. Figure 5 shows the target areas with red color (strong anomaly) to blue color (weak anomaly) range mapped from PC 4. This method is very helpful to distinguish intensity of targets where altered zones are small in contrast to unaltered unites. 


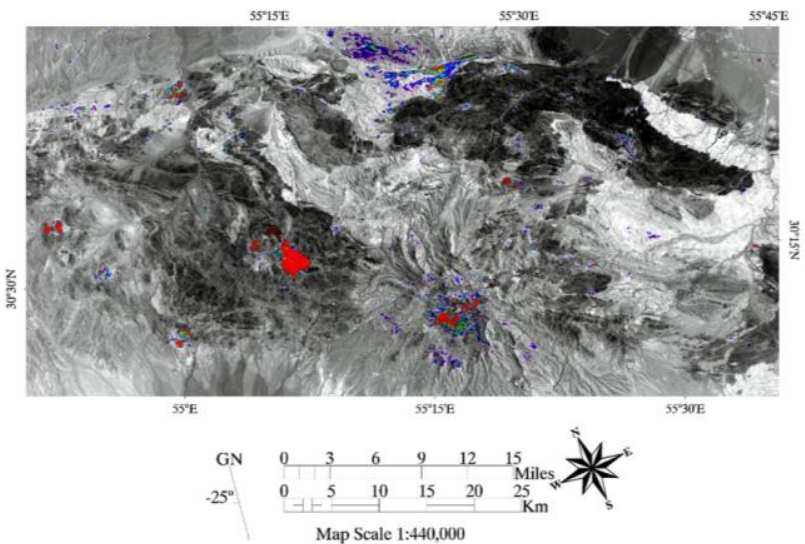

Figure 5. Al-OH Alteration intensity map of PC 4 driven from a DSPCA. Intensity of anomaly ranges from red color (strong anomaly) to blue color (weak anomaly).

Minimum Noise Fraction (MNF) transformed space is a linear combination of primary spectral bands, that is obtained from performing a simple principal component analysis to the noise reduced data. This technique is widely used for multispectral remotely sensed data processing (Green et al. 1988).

MNF data space transform was applied on SWIR and VNIR spectral bands of ASTER data to extract features of altered minerals. Most of spectral information is concentrated in lower MNF band numbers accordingly they are suitable for alteration mapping since spectral features of altered minerals are enhanced in these bands. in Figure 6 the first three generated MNF space components are visualized in RGB color format. These three bands are found to have the most useful spectral information of altered rocks. Yellow color spots are represent alteration zones related to porphyry deposits.

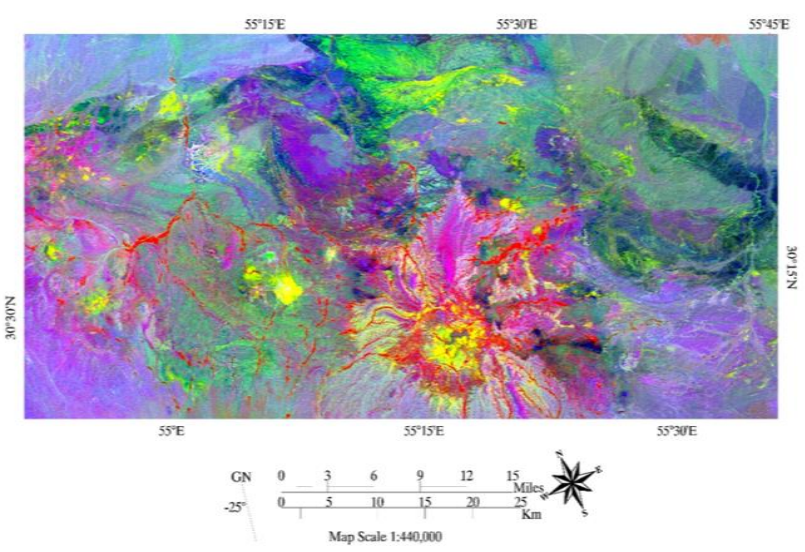

Figure 6. FCC image of RGB=MNF1, MNF2, MNF3, yellow color spots represent altered rocks.

\section{CONCLUSIONS}

Almost all the important ore indexes and deposits and main porphyry copper mineralization sites indicated in geological map of study area are successfully detected in this study. Based on the results it is evident that hydroxyl minerals are abound in alteration zone, thus phyllic zone is the most prominent and extended altered zone around intruded bodies. This study investigated the ability of OLI sensor and Landsat- 8 to delineated altered and unaltered rocks in area. Both of the Developed Selective Principal Component Analysis (DSPCA) and proposed band combinations for OLI data corroborate the result of ASTER data rotation to MNF transformed space also the results are in accordance with known mineralization sites in the region; this fact plainly proofs the potential of OLI sensor for discriminating hydrothermally altered rocks based on spectral characteristics of altered minerals.

\section{REFERENCES}

Aleks, K. et al., 2004. ASTER Mineral Index Processing Manual. Remote Sensing Applications Geoscience Australia, 37.

Aspinall, R.J.R., Marcus, W.A. \& Boardman, J.W.J., 2002. Considerations in collecting, processing, and analysing high spatial resolution hyperspectral data for environmental investigations. Journal of Geographical Systems, 4(1), pp.1529.

Clark, R.N., 1999. Spectroscopy of Rocks and Minerals, and Principles of Spectroscopy. Manual of Remote Sensing, 3(11), pp.3-58.

Crósta, A.P. et al., 2003. Targeting key alteration minerals in epithermal deposits in Patagonia, Argentina, using ASTER imagery and principal component analysis. International Journal of Remote Sensing, 24(21), pp.4233-4240.

Crósta, A.P. \& Moore, J., 1990. Enhancement of Landsat Thematic Mapper imagery for residual soil mapping in SW Minas Gerais State, Brazil- A prospecting case history in greenstone belt terrain. In Thematic Conference on Remote Sensing for Exploration Geology- Methods, Integration, Solutions, 7 th, Calgary, Canada. pp. 1173-1187.

Gabr, S.S., Hassan, S.M. \& Sadek, M.F., 2015. Prospecting for new gold-bearing alteration zones at El-Hoteib area, South Eastern Desert, Egypt, using remote sensing data analysis. Ore Geology Reviews, 71(0), pp.1-13.

Ghannadpour, S.S. et al., 2015. Assessment of prospective areas for providing the geochemical anomaly maps of lead and zinc in Parkam district, Kerman, Iran. Geosciences Journal, 19(3), pp.431-440.

Green, A.A. et al., 1988. A transformation for ordering multispectral data in term of image quality with implications for noise removal. IEEE Transactions on Geoscience and Remote Sensing, 26(1), pp.65-74.

Hunt, G.R. \& Ashley, R.P., 1979. Spectra of altered rocks in the visible and near infrared. Economic Geology, 74(7), pp.16131629.

Irons, J.R., Dwyer, J.L. \& Barsi, J.A., 2012. The next Landsat satellite: The Landsat Data Continuity Mission. Remote Sensing of Environment, 122, pp.11-21.

Jakob, S. et al., 2015. Remote sensing based improvement of the geological map of the Neoproterozoic Ras Gharib segment in the Eastern Desert (NE-Egypt) using texture features. Journal of African Earth Sciences, 111, pp.138-147.

Mezned, N., Abdeljaoued, S. \& Boussema, M.R., 2010. A 
comparative study for unmixing based Landsat ETM+ and ASTER image fusion. International Journal of Applied Earth Observation and Geoinformation, 12(SUPPL. 1), pp.131-137.

Pazand, K., Sarvestani, J.F. \& Ravasan, M.R.S., 2013. Hydrothermal Alteration Mapping Using ASTER Data for Reconnaissance Porphyry Copper Mineralization in the Ahar Area, NW Iran. Journal of the Indian Society of Remote Sensing, 41(2), pp.379-389.

Pohl, C. \& Genderen, J. Van, 1998. Review article Multisensor image fusion in remote sensing: Concepts, methods and applications. International Journal of Remote Sensing, 19(5), pp.37-41.

Regard, V. et al., 2004. Accommodation of Arabia-Eurasia convergence in the Zagros-Makran transfer zone, SE Iran: A transition between collision and subduction through a young deforming system. Tectonics, 23(4).

Rowan, L.C., Goetz, A.F.H. \& Ashley, R.P., 1977. Discrimination of hydrothermal altered and unaltered rocks in visible and near infrared multispectral images. Geophysics, 42(3), pp.522-535.

Sabins, F.F., 1999. Remote sensing for mineral exploration. Ore Geol Rev, 14(3), pp.157-183.

Salles, R. dos R. et al., 2015. Hyperspectral remote sensing applied to uranium exploration: A case study at the Mary Kathleen metamorphic-hydrothermal U-REE deposit, NW, Queensland, Australia. Journal of Geochemical Exploration, In press.

Sillitoe, R.H., 2010. Porphyry Copper Systems. Economic Geology, 105(1), pp.3-41.

Tangestani, M.H. \& Moore, F., 2001. Comparison of three principal component analysis techniques to porphyry copper alteration mapping: A case study, Meiduk area, Kerman, Iran. Canadian Journal of Remote Sensing, 27(2), pp.176-182.

Wang, G., Du, W. \& Carranza, E.J.M., 2017. Remote sensing and GIS prospectivity mapping for magmatic-hydrothermal base- and precious-metal deposits in the Honghai district, China. Journal of African Earth Sciences, 128(July), pp.97-115.

Zhang, X., Pazner, M. \& Duke, N., 2007. Lithologic and mineral information extraction for gold exploration using ASTER data in the south Chocolate Mountains (California). ISPRS Journal of Photogrammetry and Remote Sensing, 62(4), pp.271-282.

Zürcher, L. et al., 2015. Porphyry copper assessment of the Tethys region of western and southern Asia, U.S. Geological Survey Scientific Investigations Report 2010-5090-V, pp.168173 